\title{
The role of schools in promoting sexual and reproductive health among adolescents in developing countries
}

Cynthia B. Lloyd

Population Council

Follow this and additional works at: https://knowledgecommons.popcouncil.org/departments_sbsr-pgy

Part of the Demography, Population, and Ecology Commons, Family, Life Course, and Society Commons, International Public Health Commons, Maternal and Child Health Commons, Public Health Education and Promotion Commons, and the Women's Health Commons How does access to this work benefit you? Let us know!

\section{Recommended Citation}

Lloyd, Cynthia B. 2007. "The role of schools in promoting sexual and reproductive health among adolescents in developing countries," Poverty, Gender, and Youth Working Paper no. 6. New York: Population Council. 


\section{POVERTY, GENDER, AND YOUTH}

The Role of Schools in Promoting Sexual and Reproductive Health Among Adolescents in Developing Countries

Cynthia B. Lloyd 


\section{(2) Population Council}

One Dag Hammarskjold Plaza

New York, New York 10017 USA

www.popcouncil.org pubinfo@popcouncil.org

Our new name Beginning with the first number of 2007, Policy Research Division working papers are now called Poverty, Gender, and Youth working papers. For information on papers in both series, including those that are available for downloading in PDF format, see www.popcouncil.org/publications/wp/index.html

This material may not be reproduced without written permission from the author.

ISSN: $1554-8538$

(C) 2007 The Population Council, Inc. 


\title{
The Role of Schools in Promoting Sexual and Reproductive Health Among Adolescents in Developing Countries
}

\author{
Cynthia B. Lloyd
}

Cynthia B. Lloyd is Senior Associate, Population Council. The author acknowledges with gratitude Richard Gregory's data analysis and Barbara Miller's support with literature search, graphics, and editing. The author acknowledges financial support from WHO, the Hewlett Foundation, and the MacArthur Foundation. 


\begin{abstract}
This paper reviews the state of knowledge about relationships between schooling and adolescent reproductive health. With the spread of mass schooling and the growing share of adolescents who attend school, the opportunities for synergies between health and education policies and programs are growing. Data on cross-country variations in health conditions on the one hand, and variations in attendance and attainment patterns and school systems on the other hand, provide a framework for assessing alternative approaches to the promotion of adolescent sexual and reproductive health in different contexts. Disappointing findings from recent school-based reproductive health interventions in poor rural settings raise questions about the widespread applicability of current school-based approaches to promoting sexual and reproductive health.
\end{abstract}


Successful transitions to adulthood, whether they be transitions to work, to marriage and parenthood, to household management, or to citizenship, depend fundamentally on the twin building blocks of good education and good health (NRC/IOM 2005). Healthy children are more likely to attend school and, if they do so, to learn effectively and acquire knowledge and skills for life. Educated children are better able to manage and, when they grow up, sustain their own health as well as the health of their families.

To date, research on the effects of education on health has focused primarily on the cross-generational links between parents' education and their children's health; much less attention has been devoted to the contemporaneous links between being a student and remaining healthy or being a student and acquiring specific health-related knowledge and skills. As children age, not only do they gain more control and influence over their health, but they confront changing health issues. After puberty, particularly in the case of girls, sexual and reproductive health become key components of overall health. Even for boys, in settings where HIV/AIDS is widespread, sexual behavior can be an important determinant of basic health, both during adolescence and later in adulthood.

This paper reviews the state of knowledge about relationships between schooling and adolescent reproductive health. With the spread of mass schooling and the growing share of adolescents who attend school, the opportunities for synergies between health and education policy are growing. Data on cross-country variations in health conditions on the one hand, and variations in attendance and attainment patterns and school systems on the other hand, provide a framework for assessing alternative approaches to the promotion of adolescent sexual and reproductive health in different contexts.

\section{BACKGROUND AND CONTEXT}

School participation and educational attainment among adolescents have been rising rapidly throughout the developing world. At the same time, sexual and reproductive behaviors among adolescents have been changing within rapidly shifting environments both in terms of health risks and health services and in terms of changing perceptions of risk, changing fertility preferences, delays in the timing of marriage, and changing opportunity structures with respect to education and employment. While the direction of change has been consistent across most countries in the case of schooling, with the greatest improvements occurring among girls and in the lowest-income countries, changes in sexual and reproductive behaviors appear to have been more context-specific. Given the enormous variability in school systems across countries, it is possible that some of the cross-country differences observed could be explained by the very different educational environments experienced by young people throughout the developing world. The discussion that follows documents some of the changes taking place with respect to both schooling and adolescent sexual and reproductive health. 


\section{Patterns and trends in adolescents' school attendance}

One of the most dramatic trends in developing countries over the last two to three decades has been the rapid rise in both school participation and grade attainment, particularly for girls. This has occurred in countries that have prospered economically and in those that have not. Indeed, throughout the developing world the pace of change has been more rapid than the pace of change that occurred during the transition to universal schooling among today's developed countries (Clemens 2004). These changes have meant that an increasing percentage of adolescents in every country attend school during their adolescent years, with growing numbers still attending beyond the age of 15 . Nonetheless, school participation and grade attainment rates lag for the poor, with poor and "excluded" girls at the greatest disadvantage (Lewis and Lockheed 2006).

Figure 1 summarizes estimates of regional trends in the percent ever attending school over the past 20 years for the youngest adolescents by comparing the percent ever attending school among 10-14-year-olds to the percent of 30-34-year-olds who attended school 20 years earlier. ${ }^{1}$ These estimates are based on recent household survey data collected in 50 developing countries representing roughly 60 percent of the population aged 10-24 in the developing world as a whole and 88 percent of the population aged 1024 living in countries defined as low income by the World Bank (NRC/IOM 2005). Given the attention to extreme poverty in the United Nations' Millennium Development Goals, these data provide particularly good coverage of the contexts where new policy efforts will be most needed.

Overall these data show a gain of 10 percentage points for boys in school attendance, from 79 to 89 percent, and a gain of 21 percentage points for girls, from 61 to 82 percent. The gains for girls are particularly striking in Western and Middle Africa, the Middle East, and South Asia. As a result the gender gap has narrowed considerably and is likely to continue narrowing over the next decade. This expectation is based on changes that have already taken place in the percent who have ever attended, as implied by recent differences between ever-attendance rates of those aged 10-14 and those aged 20-24 (data not shown, NRC/IOM 2005). Growth rates for girls in ever-attendance rates and, by extension, grade attainment are five times the growth rates for boys, suggesting an accelerated pace at which the gender gap in attendance is narrowing, as growth rates in attendance for boys slow down.

By age 15, most adolescents have reached sexual maturity and are potentially exposed to the dual risks of sexually transmitted diseases and, in the case of girls, unwanted pregnancy. Figure 2 presents recent data from 45 Demographic and Health Surveys collected between 1998 and the present on the percent of 15-year-olds who are still attending school. ${ }^{2}$ The darker bars represent boys and the lighter bars represent girls; data are ranked from low to high within each region according to attendance rates for boys. Two observations can be made on the basis of these data. The first is that the percent of adolescents who are students at age 15 varies enormously among developing countries. From the data depicted here we see that the school enrollment of sexually mature adolescents ranges from 13 percent in Niger to 94 percent in South Africa for 
boys and from 10 percent in Niger to 92 percent in the Dominican Republic for girls. In roughly two thirds of the countries, the percent of boys in school at age 15 exceeds the percent of girls in school at the same age. Exceptions include Madagascar, Rwanda, Lesotho, and Namibia in Africa; Bangladesh and the Philippines in Asia; and Nicaragua, Honduras, Dominican Republic, and Colombia in Latin America. The second observation is that, with few exceptions (mostly in West Africa), a majority of both boys and girls are still attending school at age 15 . While female students represent a majority of 15 -yearolds in fewer countries than male students, the rapid growth in attendance rates among 10-14-year-olds will inevitably lead to further increases in the percentage of girls and boys still attending school at age 15 .

The distribution of 15-year-old students across grades varies enormously as a result of differences in starting ages and patterns of grade repetition. In Figure 3, we show the cross-country variation in grade distribution of female students aged 15 grouped into five categories: attending grade 6 or below, grades 7, 8, 9, and grade 10 or above. Normally if a child started grade 1 no later than age 7 (the latest recommended age for entry into grade 1) and progressed steadily each year from grade to grade, she/he should be in grade 8 or 9 by age 15. It is clear from the data presented in Figure 3 that 15 -yearold girls occupy a broad range of grades in most countries. While in some countries the majority of 15-year-olds are in grade 6 or below, in a few (India, Turkey, and Vietnam) the majority are in grade 10 or above (suggesting a starting age of 5). Not only does the median or modal grade vary enormously across countries, but in many countries no one grade captures more than about 20 percent of adolescents of this age (data not shown). The distributions depicted in the figure suggest the basic challenges of teaching students at a particular stage of development about sexual and reproductive health in settings where same-age adolescents are widely distributed across many grades.

The diversity across Africa is striking, with the percent of 15-year-olds who are "behind" (in grade 6 or below) varying from over 90 percent in Rwanda to less than 10 percent in South Africa. In Latin America and the Middle East, students tend to have progressed to higher grades by age 15, probably because of earlier starting ages. Nonetheless, even in many of these settings, the median or modal grade captures a relatively small percentage of students at age 15 .

In Figure 4, we compare gender gaps in the percent of 15-year-old boys and girls who are significantly behind grade for their age, defined as in grade 6 or below. Each line represents the size of the gender gap for a particular country, and the positioning of the line shows the lowest and highest percent behind grade for age. The extent to which students are over age for their grade varies enormously across countries. In most cases, more boys than girls are behind grade for age. Countries with large gender gaps in the percent behind (over 10 percentage points in favor of girls) include Tanzania, Malawi, Madagascar, Mali, Zambia, Lesotho, Namibia, South Africa, Nicaragua, and Dominican Republic. These differences represent an additional source of diversity within the classroom with respect to adolescent development.

Evidence from a meta-analysis of evaluations of school-based HIV prevention programs for African youth (Gallant and Maticka-Tyndale 2004) suggests that programs 
implemented in primary schools are typically more effective in terms of changes in knowledge and behaviors - in particular, abstinence and the use of condoms. ${ }^{3}$ These findings led the authors of the study to conclude that programs can be more effective when targeted to students at an earlier stage of development, particularly before they become sexually active. However, the study does not present data comparing the average age of students across studies or the age diversity of participants in particular programs. In the absence of relevant data, the authors' conclusions are based on certain assumptions about differences across grades and schooling levels (primary versus secondary) in students' ages and sexual experience.

As more and more school-based sex education and HIV prevention programs are introduced in primary schools, we need to better understand the demographic make-up of primary school classrooms. Figure 5 presents data on the age distribution of students in grade 6 , which is typically the end of primary school in most school systems and often a grade at which students receive some exposure to family life education. The distribution is divided into those aged 12 (typically perceived to be an ideal age for intervention given the usual age of puberty for girls and the fact that very few adolescents have experienced first sex by this age) and under, those aged 13-14, those aged 15-16, and those aged 17 and above. In some countries, the overwhelming majority of children in grade 6 are aged 12 or younger; thus a common sexual and reproductive health curriculum could be appropriate for almost all students in that grade. Included in this category are Zimbabwe, India, Philippines, Vietnam, Indonesia, Peru, Egypt, and Turkey, where more than 75 percent of female students in grade 6 are age 12 or younger. In many other settings, however, the age diversity of the classroom would present challenges to the teaching of a common curriculum, even when properly calibrated to the academic levels appropriate to the setting and grade.

\section{Reproductive health issues among adolescents}

Overall, the health of young people in developing countries has improved in recent years. Children enter their adolescent years healthier than in the past and with improved expectancy of reaching adulthood. Continued reductions in mortality in this age group are likely in most parts of the developing world, with the major exception of those countries in sub-Saharan Africa that have been hardest hit by the HIV/AIDS epidemic (NRC/IOM 2005).

Behaviors that young people adopt during adolescence have critical implications for future health and mortality. Indeed, the recent report of the US National Academies, Growing Up Global, concluded that "unprotected sex is one of the riskiest behaviors that young people can undertake, particularly in settings where HIV/AIDS is widespread" (NRC/IOM 2005). In sub-Saharan Africa, HIV/AIDS is now the leading cause of death among young people (even more so for young women than young men); it is one of the least important causes of death for young people in other regions. At the same time, in all developing-country regions, mortality and morbidity related to pregnancy and childbirth, 
including unsafe abortion, remain among the most significant risks to young women's health.

While first sex is not necessarily occurring at earlier ages than in the past, in most countries an increasing proportion of adolescents are experiencing first sex premaritally, often as a result of later ages at marriage (NRC/IOM 2005). The changing context of first sex has implications for certain reproductive health outcomes, in particular the incidence of unwanted pregnancy. These trends could also have implications for the incidence of unsafe abortions, given that the desire to stay in school is a common reason cited by adolescent girls for having an induced abortion (Bankole et al. 1998).

Detailed cross-country analysis of sub-Saharan Africa, based on surveys from 27 countries, sheds further light on trends in marriage and first sex (Mensch, Grant, and Blanc 2006). Rates of early marriage have been falling, and in many African countries for which recent data are available, these trends are being accompanied by rising proportions of young people experiencing their first sex premaritally before age 18 (ibid.). In some cases these trends can be explained by a longer period of exposure to the risk of premarital sex, given delays in marriage with no change in rates of premarital sex; in other cases these trends are due to a rise in the rate of premarital sex. At least in Africa, however, where HIV among adolescents is most widespread, there is no evidence from these data of any association between changes in the timing and context of sexual initiation and rates of HIV among adolescents (ibid.).

What is not known is whether there has been a change relative to the past in the extent to which these sexual transitions are occurring while adolescents are still attending school and the extent to which these changes are occurring primarily after adolescents leave school. Furthermore, it is not immediately obvious whether students are more or less likely than their non-enrolled peers to engage in behaviors that compromise reproductive health.

\section{The Role of Schools in Promoting Adolescent Sexual and Reproductive HEALTH}

Poor health is the outcome of many forces beyond a young person's control, including the disease environment, family circumstances, and personal vulnerability. However, individual behavior becomes a factor of growing importance to health during adolescence. In particular, unprotected sex and/or early marriage, which can lead to sexually transmitted infections, HIV/AIDS, and pregnancy, carry many risks for young people, including most immediately the risk of school dropout. Thus, we expect that students with better-off and more supportive families, as well as students doing well academically and receiving encouragement from their teachers, would be more likely than others to take steps to avoid the risk of dropout by either avoiding sex, engaging in protected sex, terminating unwanted pregnancies before detection, or negotiating with parents to refuse or delay early offers of marriage.

Similar individual and family factors may simultaneously encourage school success and the avoidance of risk or early marriage among some students, and school 
failure and risk taking or early marriage among others. Thus, we cannot necessarily assume that observed differences in behavior between students and non-students are caused by differences in school exposure and experience. Nonetheless, differences in the duration of school exposure and experience between students and non-students are likely to be among the factors influencing the behavior of adolescents during their teenage years. The mean grade levels attained by students currently enrolled typically exceed the mean grades attained among the non-enrolled by 50 percent or more, suggesting that differences in exposure to the school environment, and by extension differences in academic skills, are important (Lloyd 2006).

\section{Sexual and reproductive outcomes by student status}

Figure 6 compares proportions of unmarried 15-17-year-old girls reporting that they have ever had premarital sex according to enrollment status. ${ }^{4}$ Because the likelihood of premarital sex rises sharply with age and the percent enrolled falls with age during these years, rates are age standardized. ${ }^{5}$ While reported rates of premarital sex vary widely across countries, it would appear that, with the exceptions of Benin and Mali, girls still attending school at these ages are much less likely than their same-age peers who are not attending school to have had premarital sex. Further support for these findings come from in-depth analysis in Burkina Faso, Ghana, Malawi, and Uganda (Biddlecom et al. 2007). Age-standardized comparisons of premarital sex among boys according to school status are not possible given small sample sizes.

Because students are a selective sample of all adolescents, it is possible that differences between students and non-students in reported sexual experience vary according to the overall percent attending school at this age. The higher the percent in school, the less selective students are relative to non-students. It is reassuring to note that the strong relationship between delayed sexual initiation and current enrollment persists across countries at varying levels of enrollment, suggesting that the relationship is not the result of selectivity among students (in countries with low levels of enrollment) or among non-students (in countries with high levels of enrollment) (data not shown). On the contrary, the behavioral benefits associated with being a student seem to be strengthened with a rise in overall enrollment rates at these ages (Lloyd 2006). Furthermore, evidence suggests that the percent of girls dropping out of school because of pregnancy or early marriage has declined, at least in West Africa, as ages at marriage and first birth rise (Lloyd and Mensch 2008).

Contraceptive use among sexually active unmarried girls can also be compared by school status (see Table 1). The main problem here, however, is that, because of the relatively low levels of sexual activity at this age, sample sizes become much smaller in many countries. After eliminating data from countries where the sample size falls below 30 , we are able to compare contraceptive use among 15-17-year-olds who are sexually

active and unmarried according to school status for 26 countries. ${ }^{6}$ Rates of contraceptive use for girls are typically higher among the enrolled; less consistent patterns are apparent for boys (not shown) but for fewer countries because of sample size constraints. These 
data suggest that adolescents who are enrolled in school, particularly girls, are likely to be both better informed about and more motivated to avoid pregnancy and sexually transmitted infections through the use of contraception than their non-enrolled peers.

\section{What aspects of school quality are important for adolescent sexual and reproductive health?}

School quality typically is defined to encompass those elements, such as time to learn, school resources, and pedagogical practices, that directly contribute to the acquisition of basic learning skills, including literacy, numeracy, critical thinking, and knowledge of particular subjects. While an extensive literature has measured the relationship between school quality and various academic outcomes, including the acquisition of cognitive competencies as measured by performance on standardized tests and by grade attainment, there has been little research linking school quality and academic performance to other events occurring during adolescence, such as sexual initiation, pregnancy, and marriage. Several recent studies using two different longitudinal data sets from South Africa have documented the associations between academic achievement and sexual initiation and pregnancy (Grant and Hallman 2006; Marteleto et al. 2006). These studies show that students who do better in school are less likely to initiate sex, more likely to use a condom if sexually active, and, for girls, less likely to become pregnant or drop out if pregnant. A comparative analysis of five West African countries also showed that female students who progress through school at an appropriate age for grade are less likely to drop out because of pregnancy or early marriage (Lloyd and Mensch 2006). These relationships go both ways in that adolescents who have premarital sex while in school are more likely to drop out, particularly girls; thus adolescent risk behaviors can compromise school progress (Biddlecom et al. 2007).

The literature has seen an expansion in definitions of school quality to encompass elements supportive of other life skills, such as health and reproductive health, vocational skills, and decisionmaking and development of pro-social values (World Bank 2006; NRC/IOM 2005). School, the institution outside the family that plays the most important role in the socialization of the young, has the potential to influence students' aspirations, motivations, and risk-taking behaviors. Teachers' attitudes and skills are often critical inputs to these aspects of school quality.

In-depth studies of the role of school quality in exam performance, school dropout, and premarital sex in Kenya found that the attitudes and behavior of teachers toward their students can affect the likelihood of premarital sex while in school, as well as performance on exams and the likelihood of dropout, particularly for girls. Appleton (1995) found that variations in gender differences in primary-school leaving exams across schools, with boys on average scoring better than girls, could be partially explained by differences between schools in the extent to which teachers expressed negative attitudes toward the learning ability of girls relative to boys.

A subsequent study in Kenya (Mensch et al. 2001; Lloyd et al. 2000) that combined direct observations of teacher and student behavior in the classroom with a 
community-based survey of adolescents and their families found that girls were more likely to engage in premarital sex and more likely to drop out if they attended schools where they reported that they were not treated equitably. This effect was not found for boys. Other factors noted in this study influencing dropout rates for girls but not boys included whether teachers took the importance of more difficult subjects like mathematics less seriously for girls, whether boys were free to harass girls, and whether boys were reported to be favored in class and were offered a more supportive environment in terms of advice.

Reliable information on sexual harassment and gender-based violence in schools is generally not available; the data that have been collected on gender-based violence do not differentiate between experiences within and outside of school settings. Anecdotal evidence suggest that sexual, physical, and psychological abuse of girls is common and occurs in the community, in schools, and within the family. Researchers give accounts of girls being bullied and touched in inappropriate ways by their male peers, being pressured to have sex by boys and by their teachers, and exchanging sex for grades or money (Leach et al. 2003; Chimombo et al. 2000; DevTech 2004; World Bank 1995; Hyde 1997; Prouty 1990). Nonetheless, as we have seen in Figure 6, students are less likely to report having had sex than nonstudents, suggesting that even bad schools may provide at least some protection. Indeed, to our knowledge, the second Kenyan study cited above is the only study that has quantified the extent of sexual harassment in schools to allow comparisons across schools in students' performance according to experience of sexual harassment.

\section{School-Based Policies and Programs to Promote Sexual and Reproductive HEALTH}

During childhood and adolescence, learning and maintaining good health are mutually reinforcing: healthy children learn better and children who achieve literacy, language, and critical thinking skills are better able to make informed choices and acquire the information needed to maintain good health both during school and in later years. Indeed, we have found in a variety of developing-country settings that the links between education and health are not just correlational but causal. In studies in countries as diverse as Ghana, South Africa, Nepal, and Guatemala, evidence is mounting that literacy skills, when acquired in school and retained after school exit, are strongly linked to subsequent fertility and child health outcomes (LeVine et al. 2004; Glewwe 1999; Thomas 1999; Khandke, Pollitt, and Gorman 1999). While rates of literacy improve with levels of schooling, the correlations are far from perfect because of variations in school quality. Thus the longer-term health benefits of schooling require the acquisition and retention of basic literacy and language skills, not just the completion of a certain number of grades.

These findings suggest that the implementation of health-related curricula have little chance of success in schools where teachers lack adequate training and motivation 
and where students have not attained basic learning levels. There is growing evidence that many schools in developing countries fail to meet minimum learning standards, producing primary school graduates without basic reading and numeracy skills (NRC/IOM 2005; World Bank 2006). Furthermore, the persistence of gender bias,

particularly among teachers in terms of sexual double standards and of attitudes toward the capabilities of boys and girls, further undermines the effectiveness of many schoolbased adolescent sexual and reproductive health programs.

\section{Health-related programs in schools}

Some school systems provide basic preventive or curative health services to students. These include school meal programs (which are increasingly common), inoculation programs, de-worming programs, and, in some cases, basic health care (e.g., in Egypt, where a nurse or doctor is assigned to each school). Meanwhile, hygiene in many schools is well below minimum standards owing to lack of running water and inadequate and unsanitary toilet facilities (e.g., Mensch and Lloyd 1998 for evidence from Kenya).

The provision of sexual and reproductive health services within the school, however, is undocumented and likely to be very rare, given parental and community sensitivities. In certain instances, school-based adolescent and sexual health programs have arrangements with local health facilities to visit the school and to encourage students to attend their facilities. In one program in rural Tanzania, a sexual and reproductive health curriculum was taught to students in the last three years of primary school. As part of the program, once or twice a year teachers took the students to a local health facility to familiarize them with the services available and to allow them to see condom demonstrations, which were not allowed in the classroom (Plummer et al. 2007). The formation of health clubs within schools can also bring health services into closer proximity to the school, but the direct benefits for adolescent reproductive health have not been measured (Duflo et al. 2006).

Much more typical of school-based health investments is the provision of information on sexual and reproductive health as part of a life skills, family life education, or AIDS prevention curriculum. It is rare, however, that the learning acquired from these courses is graded or examined or that teachers are trained to teach the material or rewarded according to the quality of their work. Evaluations of various programs that have attempted to overcome some of these barriers through special teacher training or through in-school lectures by outside experts have shown some effects on knowledge and attitudes but rarely effects on self-reported behavior or biological outcomes such as HIV status (NRC/IOM 2005; Gallant and Maticka-Tyndale 2004; Speizer, Magnani, and Colvin 2003).

A recently completed and carefully documented and implemented randomized school-based adolescent sexual health intervention in rural Tanzania found positive effects on knowledge, attitudes, and self-reported sexual behaviors but did not find effects on HIV rates after three years (Ross et al. 2007). Indeed, this study has raised 
questions about the efficacy of such programs in poor rural settings. In an evaluation of the intervention in Tanzania, the authors speculated about whether the program's low measured impact might be partially due to difficulties in its implementation, given constraints within the school and the community. They concluded: "When introducing an intervention into a context in which both implementers and participants have very limited educational levels and resources, basic standards of teaching and information must first be established before more complex and interactive work can be done" (Plummer et al. 2007: 510). This evaluation revealed that while students gained better understanding of adolescent reproductive health issues than their peers in comparison schools, this understanding did not result in changed behavior or even in greater perceived selfefficacy in implementing lessons learned.

One problem with all of these school-based programs may be that messages primarily emphasize abstinence and do not help adolescents distinguish between more and less risky behaviors. An interesting experiment in Kenya in a set of randomly selected schools found that the provision of information to girls that HIV prevalence is higher among adult men than among teenage boys led to a 65 percent decrease in the incidence of pregnancies with adult partners relative to the comparison group after one year (Dupas 2006). Information was provided to primary school students in grade 8 by a trained officer from a local NGO rather than by a teacher. By contrast, the provision of special training to teachers in the Kenyan government's basic HIV/AIDS education curriculum, which emphasizes abstinence as the only risk-avoidance strategy, had no impact on pregnancy rates and little impact on other outcomes such as students' knowledge and attitudes over the same period of time (Duflo et al. 2006).

\section{Education policies with health benefits}

In the most general way, any investment in improving school access or quality in settings where learning outcomes remain poor is likely to have beneficial effects on adolescents' sexual and reproductive health for all the reasons discussed above. Improved academic performance is associated with delayed sexual initiation and a reduced likelihood of pregnancy. For example, in a three-armed randomized trial of alternative school-based HIV/AIDS intervention strategies in western Kenya-including (1) training teachers in the Kenyan government's HIV/AIDS education curriculum, (2) encouraging students to debate the role of condoms and write essays about how to protect themselves, and (3) reducing the cost of education through the distribution of free uniforms-the most effective intervention in reducing teen marriage and childbearing was a program to subsidize the cost of schools through the provision of school uniforms for girls in Standards 6-8, thus encouraging school attendance during the teen years and reducing incentives for early dropout and childbearing (Duflo et al. 2006). The intervention designed to support the further education of girls through lowering the cost of school attendance was more effective in eliciting positive health behaviors than either of the alternative interventions designed to affect health behaviors more directly by improving the quality of sexual and reproductive health education. 
The acquisition of basic literacy and numeracy in primary school is a critical building block for the development of healthy behaviors during adolescence and adulthood. Results from a longitudinal study of adolescents in Cape Town, South Africa (Marteleto et al. 2006) show that the higher the level of literacy and numeracy scores, the more likely an adolescent will be to delay sexual initiation. The acquisition of basic learning skills by a certain age depends not only on the quality of the school but also on the age at which a child begins school. Policies to encourage students to start school on time are likely to reap multiple benefits for adolescent reproductive health, given the importance of peer influences, particularly for girls, and the difficulties of presenting sensitive material to age-diverse classrooms.

\section{CONCLUSIONS AND IMPLICATIONS}

Boys and girls, particularly when they become adolescents, represent a challenging client population for both schools and health service providers. They become even more challenging as clients if they reach adolescence without the requisite literacy, language, and critical thinking skills to negotiate this complex stage of their lives. It is at this point that they are expected to assume increasing responsibility for their own health, through the proper assessment of risk and the adoption of a healthy lifestyle. Without an adequate educational foundation, many of the school-based sexual and reproductive health programs designed for adolescents are bound to fail. Thus, basic school quality at the primary level becomes a necessary building block for the achievement of good health during adolescence and beyond, both for those who end their formal education in primary school and for those who continue to secondary school or beyond.

School quality varies both across and within countries. In some poor countries, primary schools are systematically failing in their principal task of teaching children basic literacy and numeracy. In most settings, the quality of schools varies, with some schools being excellent, many being adequate, and some failing completely. Typically, the population groups that suffer the greatest ill health are the same groups that lack access to quality schools. For these reasons, the design of adolescent health policies will depend on careful analysis of the circumstances and needs of specific adolescent subpopulations, including an assessment of the learning environment and the demographic make-up of the classroom. Adolescents with the greatest health needs are those who are most disadvantaged educationally. For these young people, improvements in basic school quality may themselves be the most promising and cost-effective intervention for adolescent reproductive health.

To the extent that health agencies continue to invest in school-based adolescent reproductive health programs in settings where school quality is sub-par, further innovation is essential, as is impact evaluation. Results to date have been disappointing. For example, community-based adolescent reproductive health programs may confer more benefits than school-based interventions because they do not rely on the same teachers who are already overstretched in the classroom. Furthermore, alternative 
groupings of children, taking into account both age and grade distinctions, are possible outside the structure imposed by the formal and grade-based classroom.

Indeed, it would be informative to compare alternative program approaches using randomization across settings with similar levels of school quality-for example, the provision of teacher incentives for improved learning outcomes, versus the provision of a community-based and age-graded reproductive health program, or the provision of school-based information about the health consequences of alternative sexual risk strategies.

\section{Notes}

1 We do not know precisely the percent of 10-14-year-olds who were attending school 20 years ago because we do not have data on current enrollment but only ever enrollment. Some members of the older cohort might have attended school but dropped out before reaching age 10 .

2 These data are typically based on the response to a question about whether a child resident in the household was attending school at any time during the current academic year. In some surveys, however, the question was posed slightly differently. In surveys conducted in Bangladesh, Côte d'Ivoire, Gabon, Guatemala, India, Indonesia, Niger, South Africa, Togo, Turkey, and Vietnam, the household respondent was asked whether each resident child was "currently attending."

3 The analysis of 11 school-based interventions includes four in primary schools. However, two of the programs in primary schools took place in Standard 8; most school systems end the primary cycle at grade 6 .

4 This figure is based on data collected from reproductive-aged women. Countries that conducted surveys with ever-married women only were excluded.

5 Rates are age standardized by giving single-year-of-age rates equal weight. Sample sizes for 15-, 16-, and 17-year-olds are sufficiently large to permit calculation of individual rates.

6 For this comparison, the calculated percentages are not standardized by individual ages because the numbers are too small, but contraceptive use is less strongly associated with age than with first sex. 


\section{REFERENCES}

Appleton, S. 1995. "Exam determinants in Kenyan primary school: Determinants and gender differences." McNamara Fellowships Program. Washington, DC: Economic Development Institute of the World Bank.

Bankole, Akinrinola, Susheela Singh, and Taylor Haas. 1998. "Reasons why women have induced abortions: Evidence from 27 countries," International Family Planning Perspectives 24(3): 117-127, 152.

Biddlecom, Ann, Richard Gregory, Cynthia B. Lloyd, and Barbara S. Mensch. 2007. "Premarital sex and schooling transitions in four sub-Saharan African countries," Poverty, Gender, and Youth Working Paper No. 5. New York: Population Council. An earlier version of this paper was presented at the IUSSP Seminar on Sexual and Reproductive Transitions of Adolescents in Developing Countries, Cholula, Mexico, 6-9 November 2006.

Chimombo, Joseph, Mike Chibwana, Chris Dzimadzi, Esme Kadzamira, Esther Kunkwenzu, Demis Kunje, and Dorothy Namphota. 2000. Classroom, School and Home Factors That Negatively Affect Girls' Education in Malawi: A Report Submitted to UNICEF (Draft). Centre for Educational Research and Training (CERT). Zomba, Malawi: CERT.

Clemens, Michael. 2004. "The long walk to school: International education goals in historical perspective," Working Paper No. 37. Washington, DC: Center for Global Development. Available: http://www.cgdev.org/content/publications/ detail/2754

DevTech. 2004. The Safe Schools Program: Malawi Assessment Report, October 25thNovember 5th, 2004. Washington, DC: DevTech Systems, Inc.

Duflo, Esther, Pascaline Dupas, Michael Kremer, and Samuel Sinei. 2006. "Education and HIV/AIDS prevention: Evidence from a randomized evaluation in Western Kenya," Poverty Action Lab Working Paper, MIT.

Dupas, Pascaline. 2006. "Relative risks and the market for sex: Teenagers, sugar daddies and HIV in Kenya," Poverty Action Lab Working Paper, MIT.

Gallant, Melanie and Eleanor Maticka-Tyndale. 2004. "School-based HIV prevention programmes for African youth," Social Science and Medicine 58: 1337-1351. 
Glewwe, Paul. 1999 "Why does mother's schooling raise child health in developing countries? Evidence from Morocco," The Journal of Human Resources 34: 124159.

Grant, Monica and Kelly Hallman. 2006. "Pregnancy-related school dropout and prior school performance in South Africa," Policy Research Division Working Paper No. 212. New York: Population Council.

Hyde, Karin A. L. 1997. "Barriers to equality of educational opportunity within mixedsex secondary schools in Malawi," in S. Erskine and M. Wilson (eds.), Gender Issues in International Education: Beyond Policy and Practice. New York: Garland Press.

Khandke, V., E. Pollitt, and K. Gorman. 1999. "The role of maternal literacy in child health and cognitive development in rural Guatemala," paper presented at the biennial meetings of the Society for Research in Child Development, Albuquerque, NM, April.

Leach, Fiona, Vivian Fiscian, Esme Kadzamira, Eve Lemani, and Pamela Machakanja. 2003. "An investigative study of the abuse of girls in African schools," Department for International Development: Educational Papers, No. 54.

LeVine, Robert A., Sarah E. LeVine, Meredith L. Rowe, and Beatrice Schnell-Anzola. 2004. "Maternal literacy and health behavior: A Nepalese case study," Social Science and Medicine 58: 863-877.

Lewis, Maureen A. and Marlaine E. Lockheed. 2006. Inexcusable Absence: Why 60 Million Girls Still Aren't in School and What to Do About It. Washington, DC: Center for Global Development.

Lloyd, Cynthia B. 2006. "Schooling and adolescent reproductive behavior in developing countries," paper commissioned by the United Nations Millennium Project for the report Public Choices, Private Decisions: Sexual and Reproductive Health and the Millennium Development Goals. New York: UN Millennium Project.

Lloyd, Cynthia B. and Barbara S. Mensch. 2006. "Marriage and childbirth as factors in school exit: An analysis of DHS data from sub-Saharan Africa," Policy Research Division Working Paper No. 219. New York: Population Council.

Lloyd, Cynthia B. and Barbara S. Mensch. 2008. "Marriage and childbirth as factors in school exit: An analysis of DHS data from sub-Saharan Africa," Population Studies. Forthcoming in March. 
Lloyd, Cynthia B., Barbara S. Mensch, and Wesley H. Clark. 2000. "The effects of primary school quality on school dropout among Kenyan girls and boys," Comparative Education Review 44(2): 113-147.

Marteleto, Leticia, David Lam, and Vimal Ranchhod. 2006. "Sexual behavior, childbearing and schooling in urban South Africa," paper presented to IUSSP Seminar on Sexual and Reproductive Transitions of Adolescents in Developing Countries, Cholula, Mexico, 6-9 November.

Mensch, Barbara S., Wesley H. Clark, Cynthia B. Lloyd, and Annabel S. Erulkar. 2001. "Premarital sex, schoolgirl pregnancy, and school quality in rural Kenya," Studies in Family Planning 32(4): 285-301.

Mensch, Barbara S., Monica J. Grant, and Ann K. Blanc. 2006. "The changing context of sexual initiation in sub-Saharan Africa," Population and Development Review 32 (4): 699-727. Earlier version published in 2005 as Policy Research Division Working Paper No. 206. New York: Population Council.

Mensch, Barbara S. and Cynthia B. Lloyd. 1998. "Gender differences in the schooling experiences of adolescents in low-income countries: The case of Kenya," Studies in Family Planning. 29(2):167-184.

National Research Council and Institute of Medicine (NRC/IOM). 2005. Growing Up Global: The Changing Transitions to Adulthood in Developing Countries. Panel on Transitions to Adulthood in Developing Countries, Cynthia B. Lloyd (ed.). Washington, DC: National Academies Press.

Plummer, Mary L., D. Wight, A.I.N. Obasi, J. Wamayi, G. Mshana, J. Todd, B.C. Mazige, M. Makokha, R.J. Hayes, and D.A. Ross. 2007. "A process evaluation of a school-based adolescent sexual health intervention in rural Tanzania: The MEMA kwa Vijana programme," Health Education Research 22(4): 500-512.

Prouty, Diane B. 1990. "Reproducers reproduced: Female resistance in a Rwanda classroom," Journal of the Society for International Development 1: 74-79.

Ross, D.A., J. Changalucha, A.I. Obasi, J. Todd, M.L. Plummer, B. Cleophas-Mazige, A. Anemona, D. Everett, H.A. Weiss, D.C. Mabey, H. Grosskurth, and R.J. Hayes. 2007. "Biological and behavioural impact of an adolescent sexual health intervention in Tanzania: A community-randomized trial," AIDS 21(14): 19431955.

Speizer, Ilene S., Robert J. Magnani, and Charlotte E. Colvin. 2003. "The effectiveness of adolescent reproductive health interventions in developing countries: A review of the evidence," Journal of Adolescent Health 33(5): 324-348. 
Thomas, Duncan. 1999. "Fertility, education and resources in South Africa," in C. Bledsoe, J.B. Casterline, J.A. Johnson-Kuhn, and J.G. Haaga (eds.), Critical Perspectives on Schooling and Fertility in the Developing World. Washington, DC: National Academy Press.

World Bank. 1995. Developing Girls' Education in Guinea: Issues and Policies. Draft Sector Report. West Africa Department, Population and Human Resource Division. Washington, DC: World Bank.

World Bank. 2006. World Development Report 2007: Development and the Next Generation. Washington DC: World Bank. 
Figure 1 Changes over 20 years in the percent of boys and girls who ever attended school

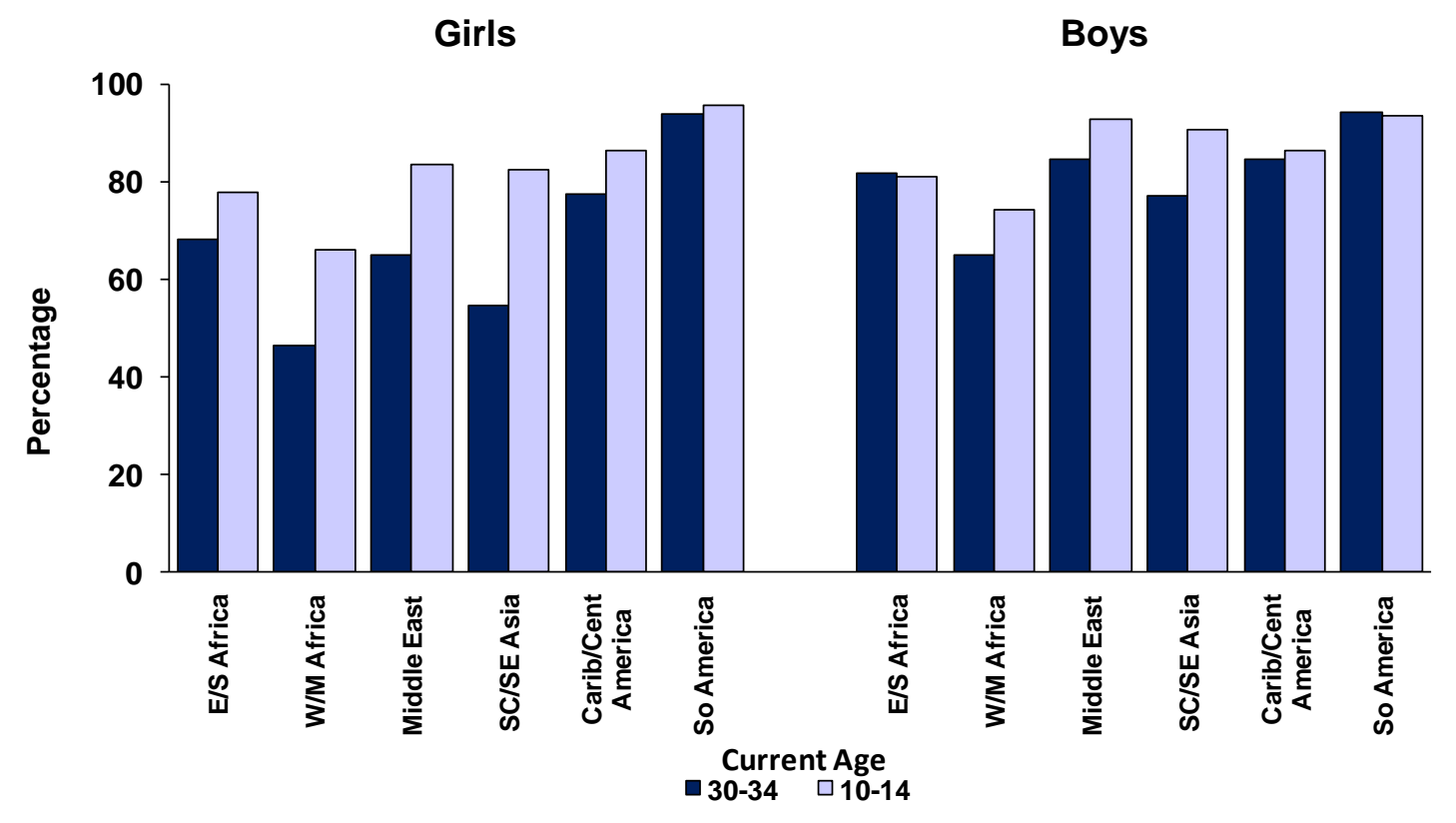

Source: NRC/IOM 2005 
Figure 2 Percent of 15-year-old boys and girls currently enrolled

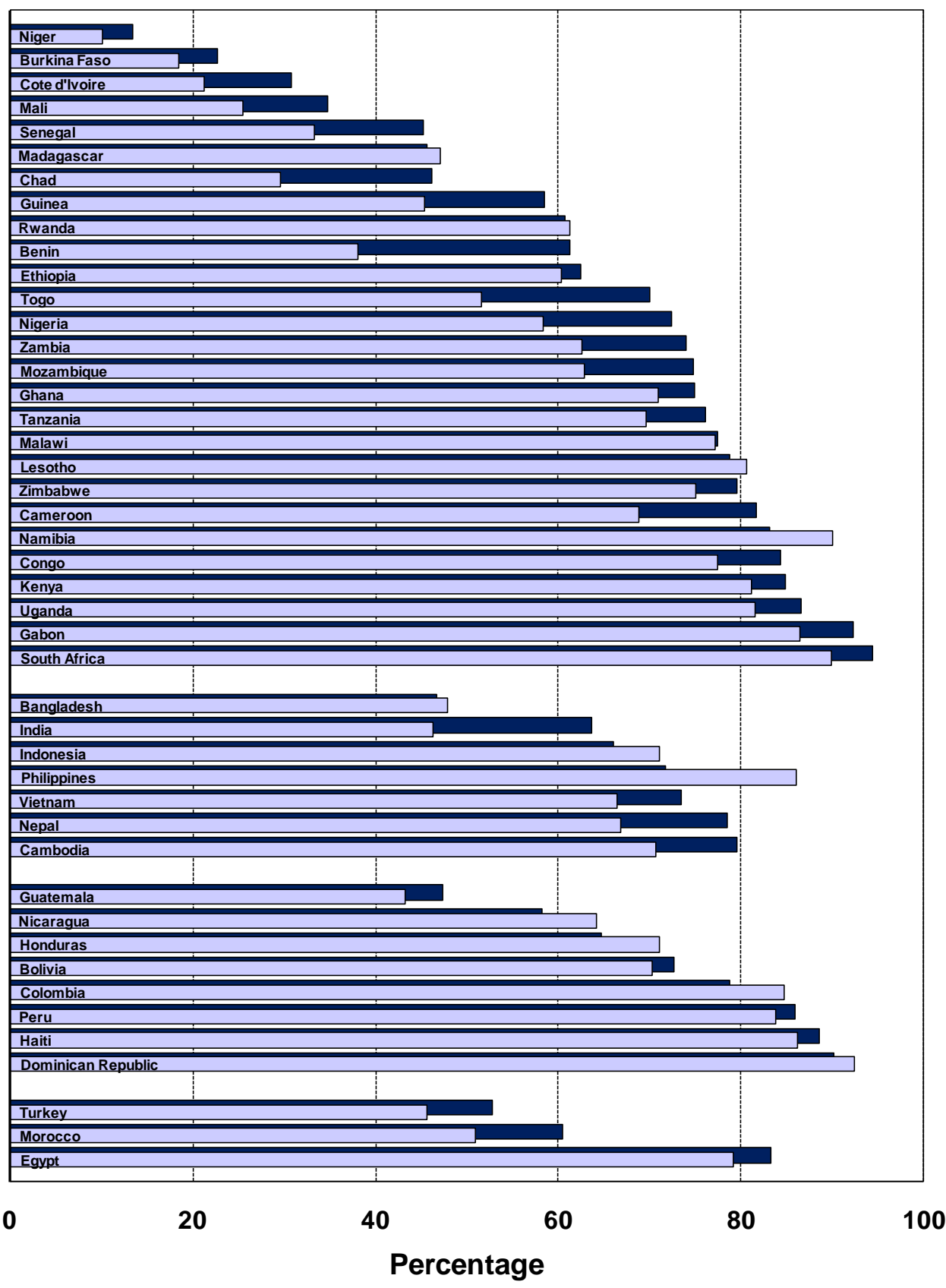

- Boys $\square$ Girls

Source: Tabulations from DHS 
Figure 3 Distribution of current grade attended by 15-year-old girls enrolled in school by country and region
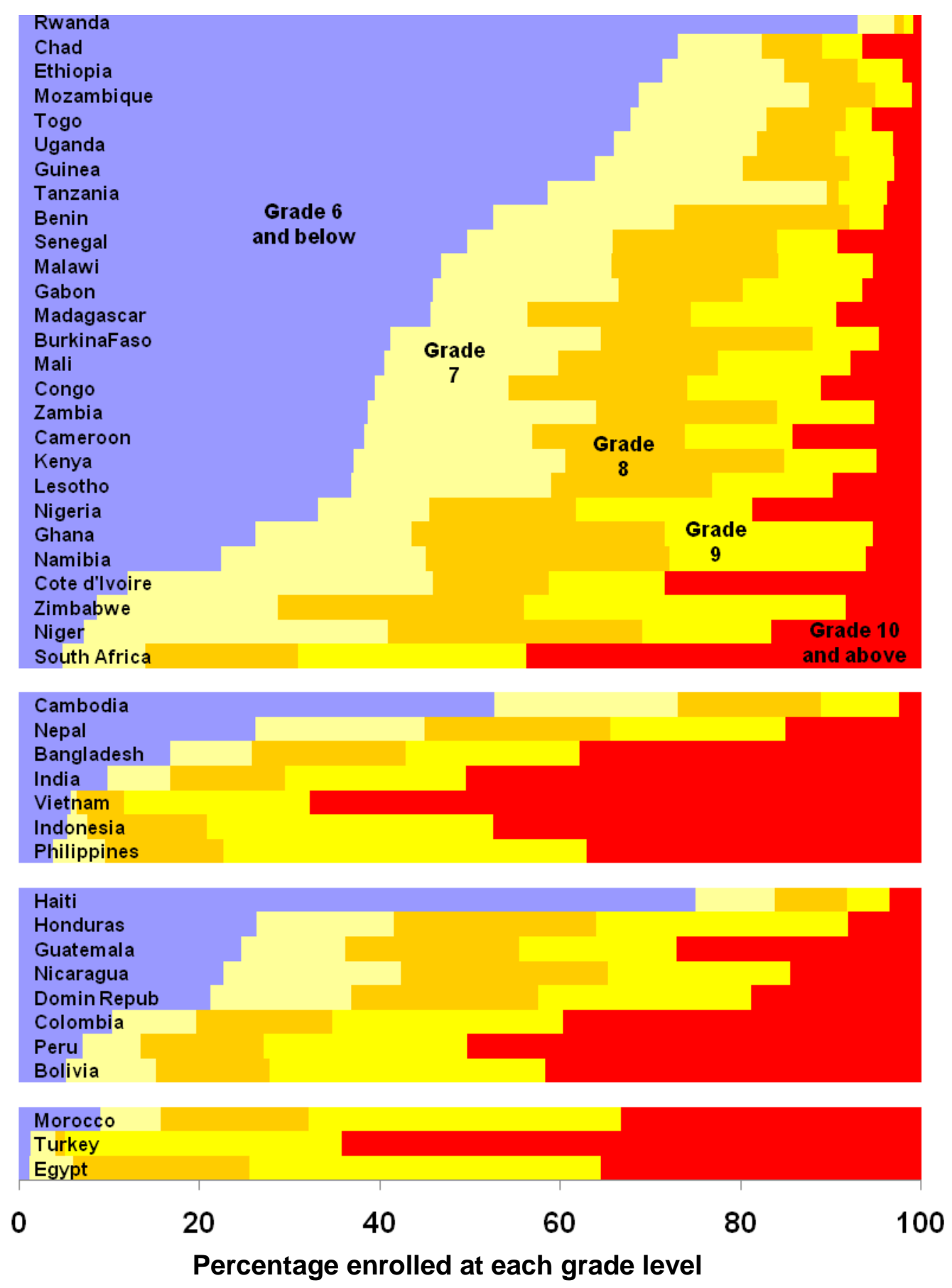

घrade 6 and below Grade 7 Grade 8 Grade $9 \square$ Grade 10 and above

Source: Tabulations from DHS 
Figure 4 Gender gap in percent of students (aged 15) behind grade for age

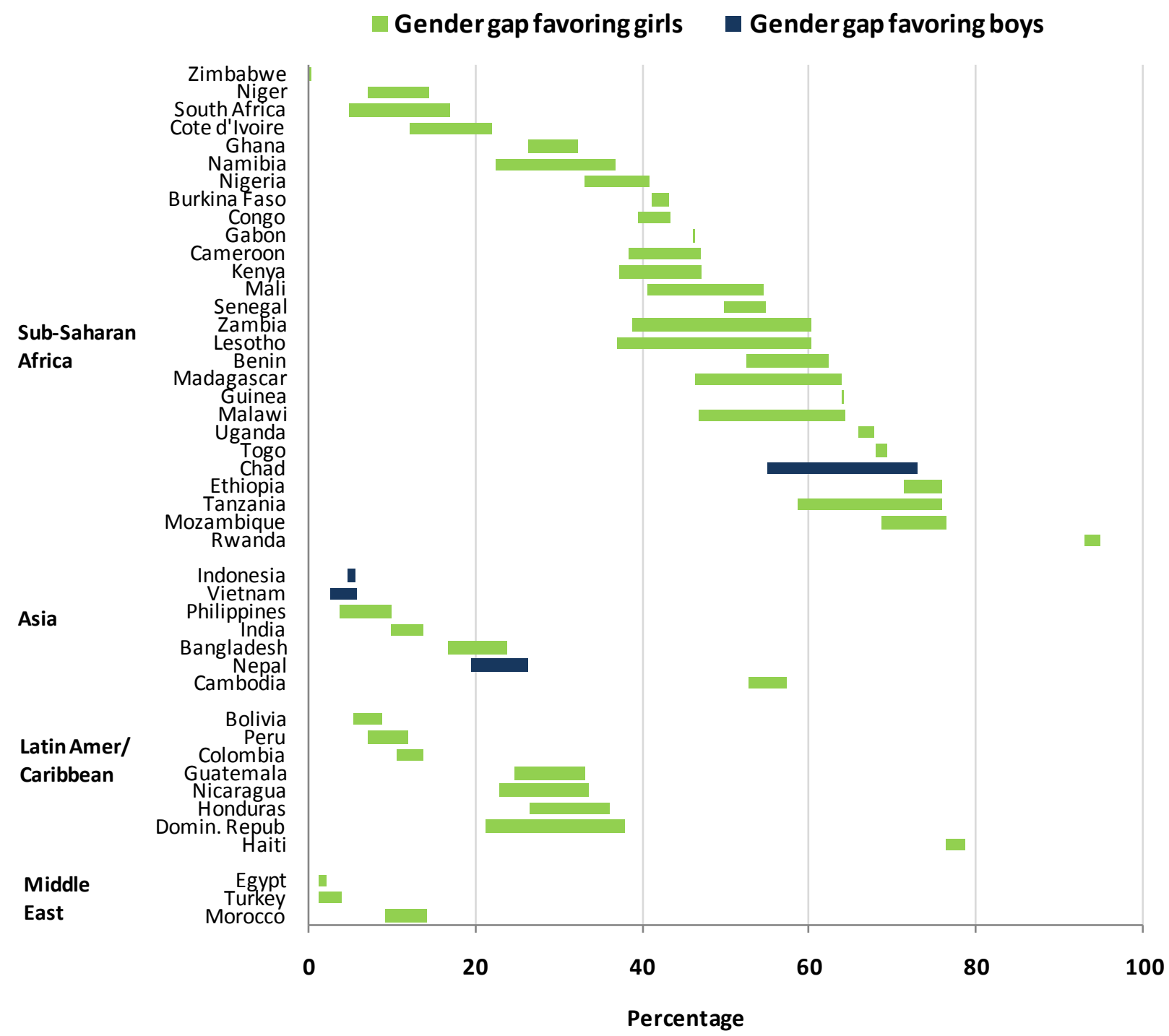

Source: Tabulations from DHS data 
Figure 5 Distribution of age of female students enrolled in grade 6 by country and region

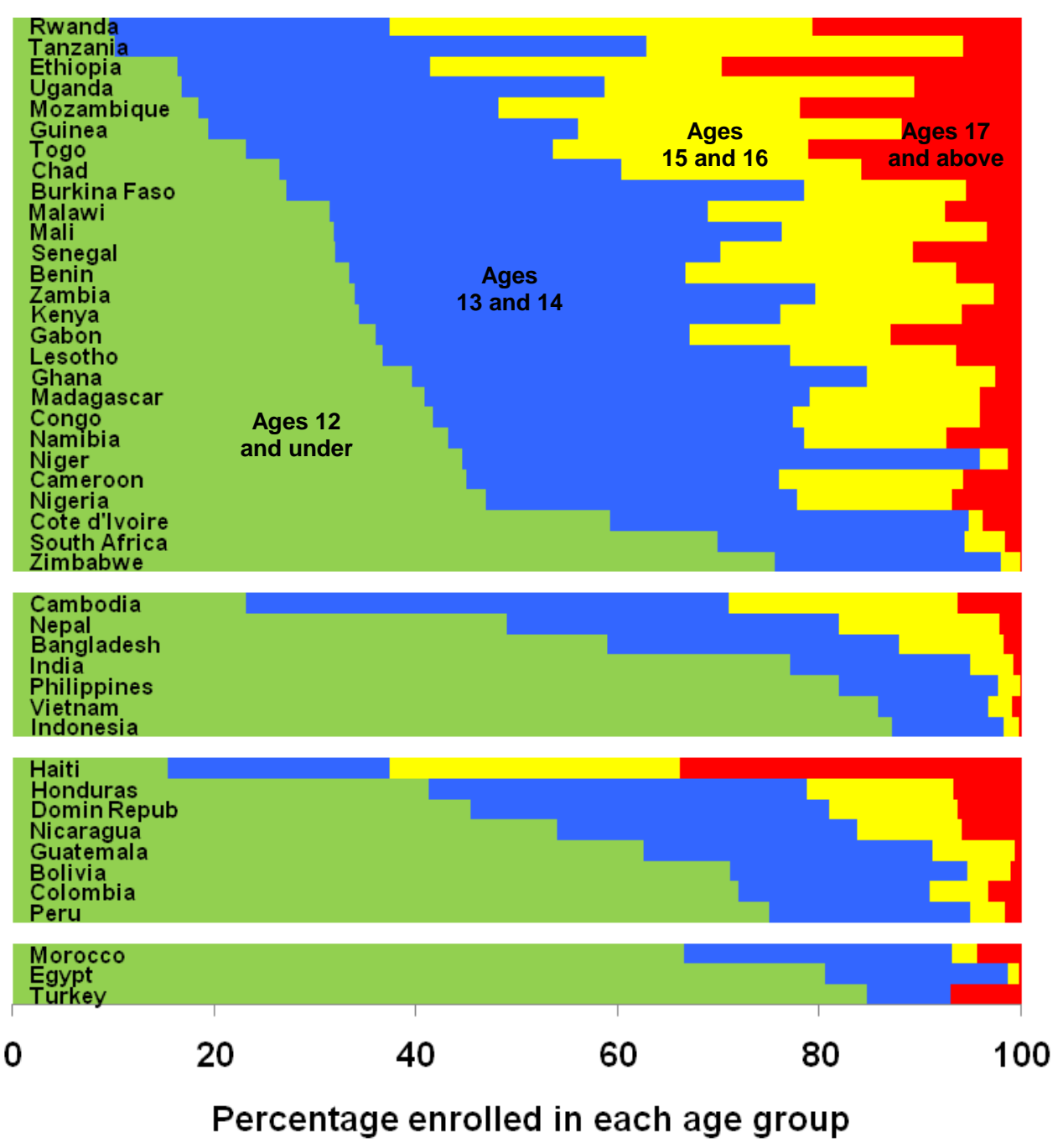

$\varpi$ Ages 12 and under $\square$ Ages 13 and 14 Ages 15 and $16 \square$ Ages 17 and above

Source: Tabulations from DHS 
Figure 6 Percentage of 15-17-year-old unmarried girls who have had sex, by enrollment status

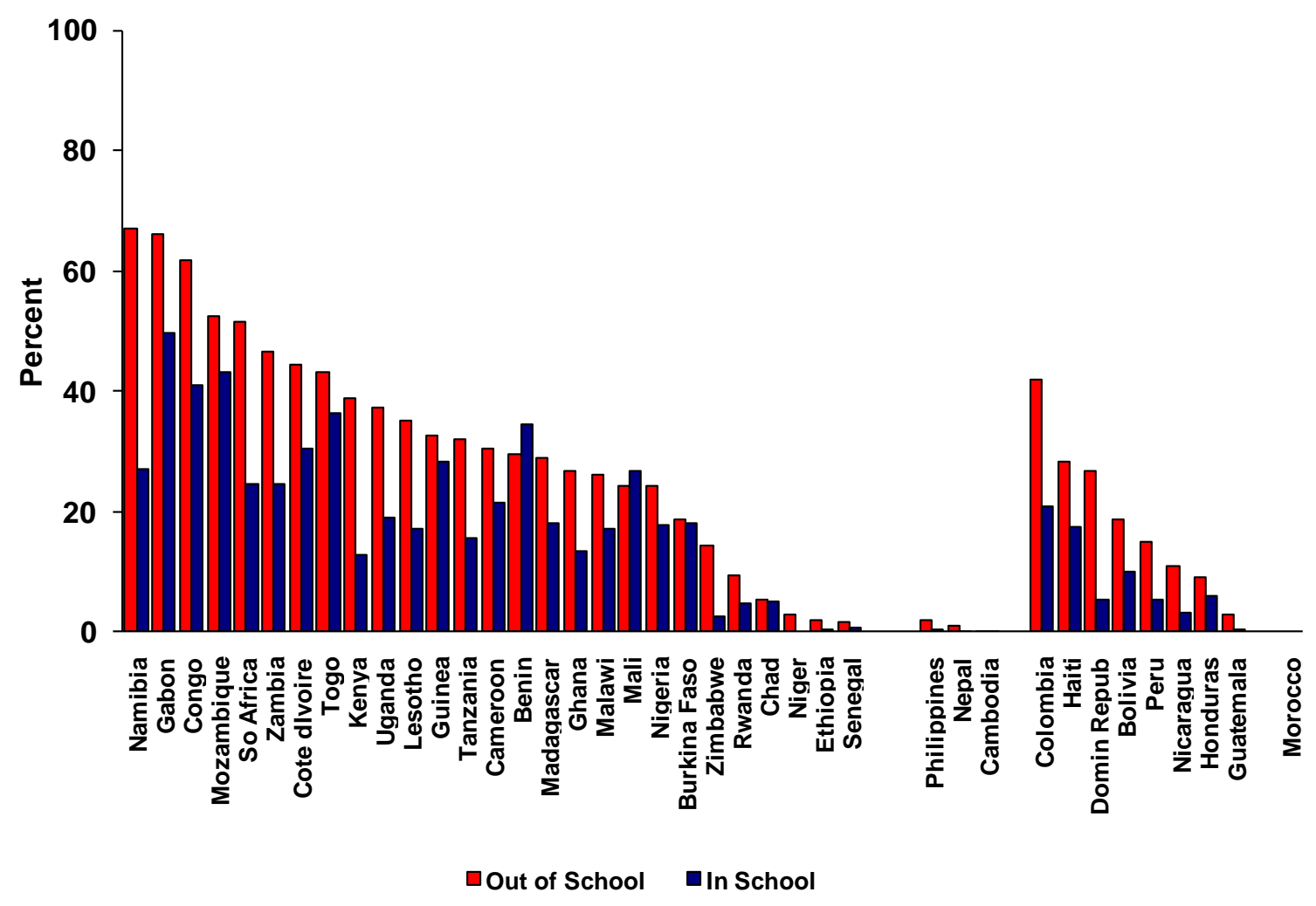

Source: Tabulations from DHS 
Table 1 Percent of 15-17-year-old girls using a modern method of contraception among those who report ever having had sex, by region, country, and school status.

\begin{tabular}{|c|c|c|c|c|}
\hline \multirow[b]{2}{*}{ Region/country } & \multirow[b]{2}{*}{ Survey year } & \multicolumn{3}{|c|}{ Percent using contraception } \\
\hline & & In school & Out of school & $\begin{array}{c}\text { Ratio } \\
\text { Out: } \text { In school }\end{array}$ \\
\hline \multicolumn{5}{|l|}{ Africa } \\
\hline South Africa & 1998 & 71.1 & 63.4 & 0.9 \\
\hline Burkina Faso & 2003 & 68.2 & 41.1 & 0.6 \\
\hline Cameroon & 2004 & 66.1 & 50.8 & 0.8 \\
\hline Namibia & 2000 & 65.1 & 69.8 & 1.1 \\
\hline Gabon & 2000 & 59.1 & 45.6 & 0.8 \\
\hline Lesotho & 2004 & 54.0 & 41.2 & 0.8 \\
\hline Mozambique & 2003 & 53.7 & 31.1 & 0.6 \\
\hline Congo & 2005 & 51.1 & 50.1 & 1.0 \\
\hline Uganda & $2000-01$ & 47.9 & 47.4 & 1.0 \\
\hline Togo & 1998 & 44.3 & 26.6 & 0.6 \\
\hline Ghana & 2003 & 40.6 & 40.4 & 1.0 \\
\hline Mali & 2001 & 35.3 & 7.6 & 0.2 \\
\hline Guinea & 2005 & 33.9 & 16.9 & 0.5 \\
\hline Nigeria & 2003 & 33.2 & 19.2 & 0.6 \\
\hline Benin & 2001 & 28.3 & 7.8 & 0.3 \\
\hline Zambia & 2001-02 & 24.6 & 22.3 & 0.9 \\
\hline Malawi & 2004 & 21.4 & 14.1 & 0.7 \\
\hline Madagascar & 2003-04 & 12.0 & 9.3 & 0.8 \\
\hline Tanzania & 2004 & 10.5 & 20.5 & 2.0 \\
\hline Kenya & 2003 & 9.9 & 25.3 & 2.6 \\
\hline Rwanda & 2005 & 3.6 & 11.3 & 3.1 \\
\hline \multicolumn{5}{|l|}{ Latin } \\
\hline \multicolumn{5}{|c|}{ America/Caribbean } \\
\hline Colombia & 2005 & 78.9 & 72.3 & 0.9 \\
\hline Honduras & 2005 & 52.9 & 42.1 & 0.8 \\
\hline Bolivia & 2003 & 33.8 & 12.8 & 0.4 \\
\hline Haiti & 2005 & 33.1 & 19.5 & 0.6 \\
\hline Peru & 2000 & 24.1 & 25.8 & 1.1 \\
\hline
\end{tabular}

Source: Tabulations from DHS data 


\section{Poverty, Gender, and Youth Working Papers}

If still in print, single copies of up to three working papers from 1989 through 2003 are available free of charge.

Beginning with the 2004 issues, working papers are no longer available in print format. Instead they are distributed electronically. As each new paper is completed, subscribers are notified by e-mail and a link to the paper is provided.

To subscribe to the Poverty, Gender, and Youth working paper e-mail notification list, or to obtain back issues from 1989 to 2003, please send your request to pgywp@popcouncil.org.

PDFs of recent issues are available at www.popcouncil.org/publications/wp/index.html

2007

6 Cynthia B. Lloyd, "The role of schools in promoting sexual and reproductive health among adolescents in developing countries."

5 Ann Biddlecom, Richard Gregory, Cynthia B. Lloyd, and Barbara S. Mensch, "Premarital sex and schooling transitions in four subSaharan African countries."

4 Sajeda Amin, John B. Casterline, and Laura Spess, "Poverty and fertility: Evidence and agenda."

3 Bussarawan Teerawichitchainan and James F. Phillips, "Ethnic differentials in parental health seeking for childhood illness in Vietnam."

2 Zachary Zimmer, Kim Korinek, John Knodel, and Napaporn Chayovan, "Support by migrants to their elderly parents in rural Cambodia and Thailand: A comparative study."

1 Sharon Ghuman and Cynthia B. Lloyd, "Teacher absence as a factor in gender inequalities in access to primary schooling in rural Pakistan."

\section{Policy Research Division} working papers

2006

219 Cynthia B. Lloyd and Barbara S. Mensch, "Marriage and childbirth as factors in school exit: An analysis of DHS data from sub-Saharan Africa."

218 Ayaga A. Bawah, James F. Phillips, Martin Adjuik, Maya VaughanSmith, Bruce MacLeod, and Fred N. Binka, "The impact of immunization on the association between poverty and child survival: Evidence from Kassena-Nankana District of northern Ghana."

217 Zachary Zimmer, "Poverty, wealth inequality, and health among older adults in rural Cambodia."

216 John Bongaarts, "Late marriage and the HIV epidemic in sub-Saharan Africa."

215 John Bongaarts, "How long will we live?"

214 Zachary Zimmer, Toshiko Kaneda, and Laura Spess, "Urban versus rural mortality among older adults in China." 
213 Paul Demeny and Geoffrey

McNicoll, "The political demography

of the world system, 2000-2050."

212 Monica Grant and Kelly Hallman, "Pregnancy-related school dropout and prior school performance in South Africa."

211 Kelly Hallman, Sara Peracca, Jennifer Catino, and Marta Julia Ruiz, "Multiple disadvantages of Mayan females: The effect of gender, ethnicity, poverty, and residence on education in Guatemala."

210 Geoffrey McNicoll, "Policy lessons of the East Asian demographic transition."

209 Cynthia B. Lloyd, Cem Mete, and Monica J. Grant, "The implications of changing educational and family circumstances for children's grade progression in rural Pakistan: 19972004."

2005

208 James F. Phillips, Ayaga A. Bawah, and Fred N. Binka, "Accelerating reproductive and child health program development: The Navrongo Initiative in Ghana."

207 John Bongaarts and Griffith Feeney, "The quantum and tempo of lifecycle events."

206 Barbara S. Mensch, Monica J. Grant, and Ann K. Blanc, "The changing context of sexual initiation in subSaharan Africa."

205 Geoffrey McNicoll, "Population and sustainability."

204 John Bongaarts, "The causes of stalling fertility transitions."
Ayaga A. Bawah and Fred N. Binka, "How many years of life could be saved if malaria were eliminated from a hyperendemic area of northern Ghana?"

202 Barbara S. Mensch, Susheela Singh, and John B. Casterline, "Trends in the timing of first marriage among men and women in the developing world."

Zachary Zimmer, "Active life expectancy and functional limitations among older Cambodians: Results from a 2004 survey."

Brian Wells Pence, Philomena Nyarko, James F. Phillips, and Cornelius Debpuur, "The effect of community nurses and health volunteers on child mortality: The Navrongo Community Health and Family Planning Project."

Zachary Zimmer, Linda G. Martin, Mary Beth Ofstedal, and Yi-Li

Chuang, "Education of adult children and mortality of their elderly parents in Taiwan."

198 Mian Bazle Hossain, James F. Phillips, and Thomas K. LeGrand, "The impact of childhood mortality on fertility in six rural thanas of Bangladesh."

197 Kristine R. Baker, Mary Beth Ofstedal, Zachary Zimmer, Zhe Tang, and Yi-Li Chuang, "Reciprocal effects of health and economic wellbeing among older adults in Taiwan and Beijing."

196 Mark R. Montgomery and Paul C. Hewett, "Poverty and children's schooling in urban and rural Senegal." 